\title{
HANDBOOK OF JAPAN-UNITED STATES ENVIRONMENT-BEHAVIOR RESEARCH
}

Toward a Transactional Approach 


\section{HANDBOOK OF JAPAN-UNITED STATES ENVIRONMENT-BEHAVIOR RESEARCH}

\section{Toward a Transactional Approach}

Edited by

Seymour Wapner

Clark University

Worcester, Massachusetts

\section{Jack Demick}

Suffolk University

Boston, Massachusetts

\section{Takiji Yamamoto}

The Japanese Institute of Health Psychology

Tokyo, Japan

and

\section{Takashi Takahashi}

University of Tokyo

Tokyo, Japan

Springer Science+Business Media, LLC 


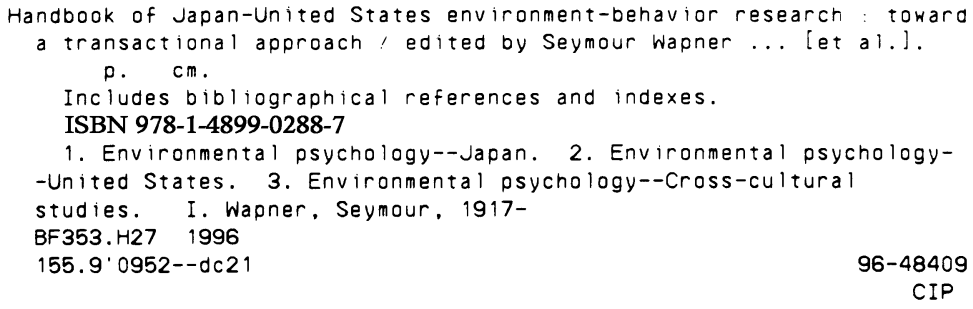

C 1997 Springer Science+Business Media New York

Originally published by Plenum Press, New York in 1997

Softcover reprint of the hardcover 1st edition 1997

\section{1}

\section{All rights reserved}

No part of this book may be reproduced, stored in a retrieval system, or transmitted in any form or by any means, electronic, mechanical, photocopying, microfilming, recording, or otherwise, without written permission from the Publisher 


\section{Contributors}

Kei Adachi, Department of Architecture, Faculty of Engineering, Kansai University, 3-3-35 Yamate-cho, Suita, Osaka, 561, Japan

Irwin Altman, Department of Psychology, University of Utah, Salt Lake City, Utah 84112

Masaaki Asai, Department of Psychology, College of Humanities and Sciences, Nihon University, Tokyo 156, Japan

Robert B. Bechtel, Department of Psychology, University of Arizona, Tucson, Arizona 85721

Kenneth H. Craik, Institute of Personality and Social Research, University of California-Berkeley, Berkeley, California 94720

Jack Demick, Department of Psychology, Suffolk University, Boston, Massachusetts 02114

Junko Fujimoto, 2-13-7 Kitahorie, Nishi-ku, Osaka 550, Japan

Kunio Funahashi, Faculty of Engineering, Department of Architectural Engineering, Osaka University, Yamadaoka, Suita 565, Japan

Toshihiro Hanazato, Institute of Art and Design, University of Tsukuba, Tsukuba, Iberaki 305, Japan

Tomohiro Hata, Department of Built Environment, Tokyo Institute of Technology,Yokohama-shi 226, Japan

Sonomi Hirata, Department of Human Sciences, Graduate School, Waseda University, Saitama 359, Japan

Sandra C. Howell, Department of Architecture, Massachusetts Institute of Technology, Cambridge, Massachusetts 02139

Tomoaki Imamichi, 2-7-13 Shiroganedai Minato-ku, Tokyo 108, Japan 
Wataru Inoue, Research Center for Educational Study and Practice, School of Education, Higashihiroshima University, Higashihiroshima 739, Japan

Yuko Inoue, 1-34-20 Nagao Higashimachi, Hirakata, Osaka 573-01, Japan

Shinji Ishii, Department of Psychology, School of Education, Hiroshima University, Hiroshima 739, Japan

Masami Kobayashi, Department of Global Environmental Engineering, Graduate School of Engineering, Kyoto University, Kyoto 606, Japan

Miki Kondo, Department of Built Environment, Tokyo Institute of Technology, Yokohama-shi 226, Japan

Satoshi Kose, Building Research Institute, Ministry of Construction, Tatehara, Tsukuba 305, Japan

Yoichi Kubota, Department of Construction Engineering, Faculty of Engineering, Saitama University, Saitama 338, Japan

Setha Low, Department of Environmental Psychology and Department of Anthropology, Graduate School and University Center of the City University of New York, New York, New York 10036

Taber MacCallum, Paragon Space Development Corporation, Tucson, Arizona 85714

Norio Maki, Department of Global Environmental engineering, Graduate School of Engineering, Kyoto University, Kyoto 606, Japan

William Michelson, Department of Sociology and Centre for Urban and Community Studies, University of Toronto, Toronto, Ontario M5S 1A1, Canada

Hirofumi Minami, Faculty of Education, Kyushu University, Fukuoka 812, Japan

Ken Miura, Department of Global Environmental Engineering, Graduate School of Engineering, Kyoto University, Kyoto 606, Japan

Ryuzo Ohno, Department of Built Environment, Tokyo Institute of Technology, Yokohama-shi 226, Japan

Hisao Osada, Tokyo Metropolitan College of Allied Medical Sciences,Tokyo 116, Japan

Jane Poynter, Paragon Space Development Corporation, Tucson, Arizona 85714 
George Rand, Department of Architecture and Urban Design, School of Arts and Architecture, University of California-Los Angeles, Los Angeles, California 90024

Amos Rapoport, Department of Architecture, University of Wisconsin-Milwaukee, Milwaukee, Wisconsin 53201

Susan Saegert, Department of Environmental Psychology, Graduate School and University Center of the City University of New York, New York, New York 10036

Miho Saito, School of Human Sciences, Waseda University, Tokorozawa, Saitama 359, Japan

Toshihiko Sako, Department of Human Health Sciences, School of Human Sciences, Waseda University, Saitama 359, Japan

Ichiro Soma, School of Human Sciences, Waseda University 359, Japan

Daniel Stokols, School of Social Ecology, University of California, Irvine, Irvine, California 92697-7050

Takeshi Suzuki, Department of Architecture, Faculty of Engineering, University of Tokyo, Tokyo 113, Japan

Takashi Takahashi, Department of Architecture, Faculty of Engineering, University of Tokyo, Tokyo 113, Japan

Kunio Tanaka, 1579-4 Mikage-cho, Kishimoto, Higashinada-ku, Kobe 658, Japan

Kanae Tanigawa, Bell Road Rokko \#204, 14-14 Teraguchi-cho, Nada-ku, Kobe 657, Japan

Karl Toews, 1558 Stonemill Road, Lancaster, Pennsylvania 17603

Seymour Wapner, Heinz Werner Institute, Clark University, Worcester, Massachusetts 01610

Takiji Yamamoto, The Japanese Institute of Health Psychology, 5F Mikuni Building, 1-3-5 Kojimachi, Chizoda-Ku, Tokyo 102, Japan

Ervin Zube, School of Renewable Natural Resources, University of Arizona, Tucson, Arizona 85721 


\section{Preface}

This volume is an outgrowth of research on the relations between human beings and their environments, which has developed internationally. This development is evident in environment-behavior research studies conducted in countries other than the United States. See Stokols and Altman (1987) for examples of such work in Australia, Japan, France, Germany, the Netherlands, Sweden, the United Kingdom, the former Soviet Union, and Latin and North America. The international development of this research area is also evident in the establishment of professional organizations in different countries such as the Environment-Behavior Design Research Association (EDRA) in the United States, the Man-Environment Research Association (MERA) in Japan, the International Association for People-Environment Studies (IAPS) in Great Britain, and the People and Physical Environment Research Association (PAPER) in Australia.

This volume focuses on environment-behavior research within Japan and the United States as well as cross-cultural studies involving both countries. As we note in detail in Chapter 1, the conference on which the work presented herein is based was preceded by three Japan-United States conferences on environment-behavior research, the first of which took place in Tokyo in 1980.

As currently conceived, the present volume stands alone as a compendium of a significant proportion of cross-cultural research on environment-behavior relations in Japan and the United States that has been developing over the last 15 years. As such, we envision the volume as a basic interdisciplinary reference for anthropolgists, architects, psychologists, sociologists, urban planners, and environmental geographers. Pedagogically, the book might be appropriate for advanced undergraduate courses in environmental and/or cross-cultural psychology. More definitely, the work can serve as a primary text in a range of graduate courses on environment-behavior research.

We would like to extend our sincere appreciation to the following institutions and individuals who contributed to the Japan-United States seminar on which this volume is based. First, the seminar would not have occurred without the generous support of the United States National Science Foundation, the Japan Society for the Promotion of Science, and both the Heinz Werner Institute for Developmental Analysis and the Frances L. Hiatt School of Psychology of Clark University. Second, there are several individuals who contributed greatly to the actual success of the seminar: Joyce Lee, who organized all details of the seminar from beginning to end (including expert typing and retyping of manuscripts); and Lorraine G. Wapner, who provided an exceptional social context that nurtured the camaraderie among - and fostered the continued collaboration of-conference participants. 


\section{Contents}

1. Introduction $\ldots \ldots \ldots \ldots \ldots \ldots \ldots \ldots \ldots \ldots \ldots \ldots \ldots \ldots \ldots$

Seymour Wapner, Jack Demick, Takiji Yamamoto, and

Takashi Takabashi

\section{PHYSICAL ASPECTS OF THE PERSON}

2. Visual Perception in Elderly Persons with Dementia . . . . . . 15 Kei Adachi

3. Dwelling Design Guidelines for Accessibility in the Aging Society: A New Era in Japan? ............... Satoshi Kose

4. Urban Housing and the Elderly . . . . . . . . . . . . . 43 Takashi Takabashi

5. Quality of Life in Japanese Older Adults . . . . . . . . . . . 51 Hisao Osada

6. A Study on a Relocation of a Nursing Home for Blind Older Adults . . . . . . . . . . . . . . . . . . . . 59 Takiji Yamamoto and Toshibiro Hanazato

\section{PSYCHOLOGICAL ASPECTS OF THE PERSON}

7. Body and Self Experience: Japan versus USA . . . . . . . . . . Jack Demick, Shinji Ishii, and Wataru Inoue

8. Cross-Cultural Survey on Color Preferences in Three Asian Cities: Comparisons among Tokyo, Taipei, and Tianjin. Icbiro Soma and Mibo Saito

9. Mode of Being in Places: A Case Study in Urban Public Space. Takesbi Suzuki 


\section{SOCIOCULTURAL ASPECTS OF THE PERSON}

10. Urban Renewal and the Elderly: An Ethnographic Approach . . . . 133 Hirofumi Minami

11. Integrating Environmental Factors into Multidimensional

Analysis .

William Micbelson

\section{PHYSICAL ASPECTS OF THE ENVIRONMENT}

12. Experiencing Japanese Gardens: Sensory Information and

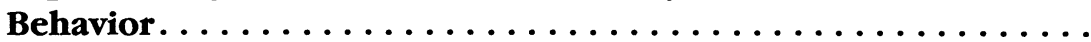

Ryuzo Obno, Tomobiro Hata, and Miki Kondo

13. Preference for Trees on Urban Riverfronts . . . . . . . . . . . Yoichi Kubota

14. Landscape Values: Congruence and Conflict in Desert Riparian Areas . . . . . . . . . . . . . . . . . . Ervin H. Zube

15. Environmental Transition and Natural Disaster: Restoration Housing for the Mt. Unzen Volcanic Eruption. Masami Kobayashi, Ken Miura, and Norio Maki

16. Environmental Psychology and Biosphere 2............ 235 Robert B. Bechtel, Taber MacCallum, and Jane Poynter

\section{INTERPERSONAL ASPECTS OF THE ENVIRONMENT}

17. Rethinking Stereotypes of Family Housing in Japan and the USA . . . . . . . . . . . . . . . . . . . . .

Sandra C. Howell

\section{SOCIOCULTURAL ASPECTS OF THE ENVIRONMENT}

18. Sociopsychological Environments of Japanese Schools as Perceived by School Students . . . . . . . . . . . . . . 261 Masaaki Asai and Sonomi Hirata

19. "Big School, Small School" Revisited: A Case Study of a Large-Scale Comprehensive High School Based on the Campus Plan . . . . . . . . . . . . . . . . . . Toshibiko Sako

20. Sojourn in a New Culture: Japanese Students in American Universities and American Students in Japanese Universities . . . . Seymour Wapner, Junko Fujimoto, Tomoaki Imamichi, Yuko Inoue, and Karl J. Toews 
21. Public Space as Art and Commodity: The Spanish American Plaza........................... 313 Setba M. Low

22. Urbanization and Quality of Life in Asia . . . . . . . . . . 325 Kanae Tanigawa and Kunio Tanaka

VII. FUTURE THEORETICAL AND EMPIRICAL DIRECTIONS FOR ENVIRONMENT-BEHAVIOR RESEARCH

23. Directions of Environmental Psychology in the Twenty-First

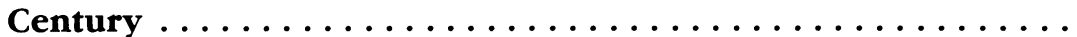

Daniel Stokols

24. Transactional Perspective, Design, and "Architectural Planning Research" in Japan Kunio Funabasbi

25. Some Arguments for a Comparative Developmental Environmental Psychology with a Long-Term View of History and Cultural Psychology. George Rand

26. Prospects for Environmental Psychology in the Third Millennium.

Kennetb H. Craik

27. What Is the Situation?: A Comment on the Fourth Japan-USA Seminar on Environment-Behavior Research . Susan Saegert

28. Theory in Environment-Behavior Studies: Transcending Times, Settings, and Groups Amos Rapoport

29. Environment and Behavior Studies: A Discipline? Not a Discipline? Becoming a Discipline? Irwin Altman

Appendix: List of Presentations of Previous Japan-U.S.

Seminars on Environment-Behavior Research.

Name Index

Subject Index $\ldots \ldots \ldots \ldots \ldots \ldots \ldots \ldots \ldots \ldots \ldots \ldots \ldots \ldots \ldots$ 


\section{HANDBOOK OF}

JAPAN-UNITED STATES

ENVIRONMENT-BEHAVIOR

RESEARCH

Toward a Transactional Approach 